\title{
EDUCAÇÃO INFANTIL E A DIVERSIDADE ÉTNICO-RACIAL: EXPERIÊNCIAS DE FORMAÇÃO E SEUS DESAFIOS
}

\section{Lucimar Rosa Dias}

Universidade Federal do Paraná

\section{Resumo}

Este artigo trata de experiências de formação continuada com professoras da educação infantil, como ações de extensão no âmbito do Grupo de Estudos em Educação, Diversidade e Inclusão GEPEDI da Universidade Federal de Mato Grosso do Sul, com objetivo de desenvolver práticas pedagógicas com foco na diversidade étnico-racial para a efetivação das Diretrizes Curriculares Nacionais para a Educação Infantil (2009) e também das Diretrizes Curriculares Nacionais para o Ensino da História e Cultura Afro-brasileira e Africana (2004). Bem como, de pesquisa desenvolvida em paralelo a esse processo de formação que alimentava as intervenções. Foram considerados os eixos da ludicidade e da interação como norteadores do trabalho e as múltiplas linguagens: o faz de conta, as práticas sociais de leitura, escrita e oralidade, conhecimento de arte e musicalização. Os resultados apontam que as professoras participam com entusiasmo das atividades propostas, concordam com a necessidade de alterar o currículo da educação infantil na perspectiva apresentada, mas em suas ações cotidianas se sentem inseguras, e apenas na medida em que recebem apoio local ficam encorajadas a desenvolver algum tipo de experiência com o tema.

Palavras-chave: Formação de Professoras, Educação Infantil, Diversidade étnico-racial.

\footnotetext{
* Doutora em Educação, Pesquisadora das relações raciais e educação infantil. Professora do Curso de Pedagogia/DEPLAE e membro do Núcleo de Estudos Afro-Brasileiros da UFPR. lucimar_dias@uol.com.br

Olh@res, Guarulhos, v. 2, n. 2, p. 203-226. Dezembro, 2014.
} 


\title{
EARLY CHILDHOOD EDUCATION AND ETHNIC-RACIAL DIVERSITY: EXPERIENCES AND TRAINING YOUR CHALLENGES
}

\begin{abstract}
This article deals with the experiences of continuing education teachers with early childhood education, como extension actions within the Study Group on Education, Diversity and Inclusion - GEPEDI, the Federal University of Mato Grosso do Sul, whose purpose was to discuss and develop pedagogical practices with a focus on ethnic and racial diversity for the realization of the National Curriculum Guidelines for Early Childhood Education (2009), and also the National Curriculum Guidelines for Teaching History and Afro-Brazilian Culture and African (2004). As well, the research developed in parallel to this process of training interventions that fed. The axes of play fulness and interaction as guiding the work and the multiple languages were considered such as themake-believe, the social practices of reading, writing and speaking skills, know ledge of art and musicalizacion. The results indicate that teachers enthusiastically participate in the proposed activities, agree on the need to change the curriculum of early childhood education in the perspective presented, but in their every day action she feelin secure and only to the extent that receive local support are encouraged to develop some experience with the theme.
\end{abstract}

Keywords: Training of teachers; early childhood education, ethnic and racial diversity. 
Este artigo relata experiências de formação continuada de professores/ras da educação infantil, realizadas entre 2009 e 2013, realizadas pelo Grupo de Estudos em Educação, Diversidade e Inclusão - GEPEDI da Universidade Federal de Mato Grosso do Sul em parceira com a Secretaria Municipal de Educação de Três Lagoas/MS (SMEC) cujo objetivo foi proporcionar aos/as participantes ferramentas para a concretização das orientações dadas pela Lei de Diretrizes e Bases da Educação em seus artigos 26-A e 79-B, as recomendações presentes nas Diretrizes Curriculares Nacionais para a Educação Infantil, especialmente em seu Art.8, e nas Diretrizes Curriculares Nacionais para o Ensino da História e Cultura Afro-brasileira e Africana. Assim como trazemos alguns elementos oriundos de pesquisas realizadas em paralelos a essas intervenções. Com isso pretendemos compartilhar algumas reflexões acerca dos desafios que a práxis na formação continuada nos colocam quando nos propomos a incluir no currículo da educação infantil práticas pedagógicas que deem conta do que preconiza as Diretrizes Nacionais desta etapa quando prevê que o currículo deverá incluir “o reconhecimento, a valorização, o respeito e a interação das crianças com as histórias e as culturas africanas, afro-brasileiras, bem como o combate ao racismo e à discriminação”. (Diretrizes Curriculares Nacionais para a educação infantil, p.21, 2010).

Foram realizados três cursos na modalidade educação continuada nos quais abordou-se temáticas relacionadas a diversidade, sendo que os principais focos foram as questões raciais, mas dois outros âmbitos estiveram presentes, as necessidades educacionais especiais e a questão indígena. Para o trabalho formativo foram considerados os eixos da educação infantil, a ludicidade e a interação, assim como, as múltiplas linguagens tais como: o faz de conta, as práticas sociais de leitura, escrita e oralidade, conhecimento de arte e musicalização e os elementos oriundos do processo da pesquisa intitulada: Investigando práticas pedagógicas promotoras da diversidade em Centros de Educação Infantil do município de Três Lagoas/MS. O principal o objetivo da pesquisa foi investigar a existência e as formas de realização de práticas promotoras da diversidade na Educação Infantil com foco em raça/etnia e necessidades educacionais especiais, bem como estabelecer momentos de ação 
conjunta entre os professores da rede de ensino do município, acadêmicos e as professoras do curso de Pedagogia envolvidos na pesquisa. A proposta central do projeto foi a análise coletiva das práticas desenvolvidas pelos Centros de Educação Infantil, visando avançar no processo de construção de uma educação inclusiva, aprimorando o já existente e divulgando as possibilidades de incluir tais práticas em outros espaços educacionais da rede municipal.

Desde a primeira ação foram criadas situações no sentido de que os professores e professoras participantes pudessem vivenciar algumas experiências e que estas servissem de balizas para que realizassem em suas instituições práticas promotoras da igualdade racial. Em paralelo aos cursos de formação foi desenvolvido o projeto de pesquisa que pretendeu investigar se existiam e quais práticas de diversidade podíamos encontrar em instituições de educação infantil do município e como elas eram desenvolvidas, porém não trataremos dessa pesquisa no presente artigo. Tanto a formação, quanto pesquisa se realizavam como ações do Grupo de Pesquisa em Educação, Diversidade e Inclusão (GEPEDI) e contou com a colaboração de alunas do curso de graduação em Pedagogia $^{2}$, membros do grupo e da professora Raquel Elizabeth SaesQuiles vicelíder do grupo.

Traremos nesse artigo algumas reflexões sobre essas experiências que colaboraram na formação de professores/ras e a temática da diversidade, principalmente com foco na questão da igualdade racial, área em que atuamos e produzimos nossas pesquisas, no entanto, como o trabalho foi realizado em parceria com a professora supracitada que tem seu foco de pesquisa nas questões relativas a educação especial, quando for pertinente para explicitação da experiência traremos os exemplos que podem envolver esse campo, assim como a última atividade de formação na qual incluímos a perspectiva indígena será também mencionada como contributos da aprendizagem resultantes desta caminhada.

Antes de adentrarmos nas questões próprias das experiências de formação, vale localizar os pressupostos que nos levaram a instituir em nossas práticas tal desafio. A Constituição Federal fixa três objetivos nucleares para a educação, quais sejam: garantir o pleno desenvolvimento da pessoa, o preparo

$2\urcorner$ Foram várias as/os acadêmicas/cos que colaboraram na construção desta experiência ao longo dos anos do GEPEDI sou profundamente grata a todas/os que participaram do GEPEDI desde sua fundação, em 20 de novembro de 2009, até o seu último dia de atividades em fevereiro de 2014. Em nome delas agradeço a todas e todos. Mirian Bazé, Bárbara Lima, Andrea Barbosa, Gleici Kelly.

Olh@res, Guarulhos, v. 2, n. 2, p. 203-226. Dezembro, 2014. 
para o exercício da cidadania e a qualificação para o trabalho. "A educação infantil, primeira etapa da educação básica, tem como finalidade o desenvolvimento integral da criança até cinco anos de idade, em seus aspectos físico, psicológico, intelectual e social, complementando a ação da família e da comunidade" (BRASIL, 1996). Cristalina, incisiva e eloquente, a Lei de Diretrizes e Bases da Educação assim se refere a um dos principais objetivos da educação infantil.

No plano das normas internacionais, o Brasil ratificou a Convenção sobre a Proteção e Promoção da Diversidade das Expressões Culturais, que classifica a identidade cultural como direito fundamental da pessoa humana. No mesmo sentido, prescreve a Declaração Universal sobre a Diversidade Cultural em seu Artigo $3^{\circ}$ que essa

[...] amplia as possibilidades de escolha que se oferecem a todos; é uma das fontes do desenvolvimento, entendido não somente em termos de crescimento econômico, mas também como meio de acesso a uma existência intelectual, afetiva, moral e espiritual satisfatória. (UNESCO, 2002).

Note-se que a proteção contra a violência psíquica, o direito à identidade cultural e a preparação da criança para assumir um espírito de compreensão, paz e amizade entre os grupos étnicos, não constituem um plexo caótico de admoestações, destituído de valor jurídico, mas sim uma previsão normativa, à qual a política educacional deve observância obrigatória.

Com isso, queremos destacar que o pleno desenvolvimento da pessoa, no contexto de sociedades plurirraciais e multiculturais como a nossa, vincula-se à capacidade dos sistemas de ensino dialogarem, valorizarem e protegerem os marcos culturais formadores da nacionalidade, sem o que compromete-se não o interesse de um ou outro grupo particular, mas a própria qualidade da educação.

Vale realçar ainda a existência de normas constitucionais que prescrevem textualmente a valorização da diversidade étnica e racial e da identidade dos diferentes grupos formadores da sociedade brasileira. Ancoradas neste preceito, as Diretrizes Curriculares Nacionais para a Educação Infantil (2009) estabelecem, no art. $8^{\circ} \S 2^{\circ} \mathrm{II}$, que se deve "reafirmar a identidade étnica e a língua materna como elementos de constituição das crianças", isto precisa estar evidenciado nas propostas pedagógicas das instituições de educação infantil, Olh@res, Guarulhos, v. 2, n. 2, p. 203-226. Dezembro, 2014. 
garantindo às crianças acesso aos diversos processos de conhecimento e aprendizagem.

Está em questão, portanto, não uma especificidade ou tema de interesse de negros ou indígenas, algo secundário, incidental, marginal à gestão da educação: sem o enfrentamento desta problemática a política educacional continuará ignorando um dos pilares jurídico-políticos da educação brasileira.

Porém é sabido que só as leis não bastam para alterar as práticas pedagógicas é necessário o engajamento, o aprendizado e o comprometimento pessoal dos professores/ras. Não é possível o Brasil construir uma política educacional igualitária, que eduque crianças e jovens para valorizarem a diversidade e construírem uma sociedade em que a democracia racial seja um fato e não um mito, sem a participação efetiva dos profissionais da educação.

Uma política educacional igualitária quer significar mais do que o ensino da História e da Cultura Afro-Brasileira e Indígenas no ensino fundamental e no ensino médio. Ela começa na educação infantil e precisa perpassar o sistema educacional como um todo. A formação de professoras e professores, as propostas pedagógicas, a política de materiais pedagógicos, o financiamento da educação, o controle social da política educacional, enfim, o conjunto de marcos legais, valores e práticas pedagógicas e atores que no dia a dia implementam o serviço público republicano denominado educação são imprescindíveis. De acordo com a Declaração de Salamanca (1994)

O desafio que confronta a escola inclusiva é no que diz respeito ao desenvolvimento de uma pedagogia centrada na criança e capaz de bem sucedidamente educar todas as crianças, incluindo aquelas que possuam desvantagens severa. $\mathrm{O}$ mérito de tais escolas não reside somente no fato de que elas sejam capazes de prover uma educação de alta qualidade a todas as crianças: o estabelecimento de tais escolas é um passo crucial no sentido de modificar atitudes discriminatórias, de criar comunidades acolhedoras e de desenvolver uma sociedade inclusiva. (DECLARAÇÃO DE SALAMANCA, Sobre Princípios, Políticas e Práticas na Área das Necessidades Educativas Especiais, s/p)

O enfrentamento para a construção de instituições acolhedoras das mais diversas singularidades demanda que a educação infantil, como de resto a educação escolar como um todo, seja considerada a partir de dois ângulos distintos e complementares: o primeiro como espaço dentro do qual deve ser assegurada a interação respeitosa e positiva com a diversidade humana, 
adequando-se os espaços físicos, materiais didáticos e paradidáticos e formando professores, gestores e funcionários para serem agentes de promoção da igualdade racial; o segundo ângulo situando a educação infantil como contexto de transformação social, no sentido em que educar na infância para valorar positivamente a diferença, dissociando diferença de inferioridade de tal sorte que, a médio e longo prazo, o preconceito e a discriminação sejam erradicados da sociedade. Nesse sentido a referência para o trabalho com as crianças é focar na construção de representações positivas dos distintos pertencimentos raciais e étnicos da sociedade brasileira, com ênfase nas culturas negras e indígenas, sendo esta a perspectiva difundida pelo GEPEDI/UFMS, desde 2009.

\section{A questão da formação de professoras/as e a diversidade étnico-racial}

A finalidade dos que atuam na perspectiva de uma educação multicultural e antirracista é que esta seja de fato emancipatória. Nossa intenção é de assegurar para todos a possibilidade de encontrar nos ambientes educacionais um lugar no qual se aprenda de forma sistemática, planejada e organizada que as diferenças raciais e culturais são construídas socialmente, para desconstruir a ideia de inferioridade atribuída a determinados grupos. Estamos na luta para construir uma educação na qual as pessoas possam compreender suas diferenças e se posicionarem contrárias à hierarquização e inferiorizarão entre os seres humanos a partir de qualquer tipo de marca.

No ambiente educacional, há várias situações nas quais é possível identificar a discriminação racial. Quando, por exemplo, uma professora escolhe uma criança branca para ser carinhosamente tocada, em detrimento de uma criança negra, ela pratica uma ação de discriminação racial, porque faz uma distinção a partir de caracteres identitários para beneficiar uma criança em detrimento de outra. Nos depoimentos de professoras entrevistadas por Dias (2007, p.42), elas relatam ações ocorridas nos seus locais de trabalho que são exemplares.

Na educação infantil, a gente já sentiu essa questão da diferença do tratamento dos profissionais em relação à criança negra e à criança branca. Essa questão do estereótipo. Do modelo único de beleza, que é branco, loiro dos olhos claros ou verdes. Essa questão é muito forte na educação infantil. As crianças negras não têm tanto colo, chamego, aconchego como tem a criança branca. (Educadora Mame, de Campinas - entrevista concedida em 13/09/06).

Olh@res, Guarulhos, v. 2, n. 2, p. 203-226. Dezembro, 2014. 
Quando aparece um bebê Johnson na escola, todo mundo [diz]; - aí que lindo! Um bebê Johnson que eu falo é um menino loiro, de olho azul, bem gordo. Gordinho, bem fofo. Então esse bebê passeia pela escola inteira. Ele passeia com a monitora do outro setor, com a diretora. Como sente a criança que nunca sai? (Educadora Aminata, de Campinas entrevista concedida em 12/09/06).

Os depoimentos acima demonstram profissionais alertas a esse tipo de situação, o que não é o caso da maioria. O segundo, depoimento traz-nos um elemento importante, ao citar o "bebê Johnson", para exemplificar o tipo de bebê que recebe mais atenção nas instituições de educação infantil a profisssional nos revela como o imaginário brasileiro é influenciado e está permeado pela ideia do belo como branco.

Diante desta constatação tomamos de empréstimo a análise de Schucman (2014) para o processo de formação dos psicólogos para pensar a realizada, também, nos cursos de licenciatura

Apesar das preocupações e da luta contra a discriminação racial serem fundamentais para uma sociedade mais justa e humana, a Psicologia pouco se debruçou sobre a questão das relações raciais no Brasil. Nos currículos dos cursos de psicologia brasileiros, raramente encontramos qualquer menção ao tema da raça e do racismo nas disciplinas obrigatórias. A formação de psicólogos ainda está centrada na ideia de um desenvolvimento do psiquismo humano igual entre os diferentes grupos racializados. Assim como as categorias de classe e de gênero são fundamentais na constituição do psiquismo humano, a categoria raça é um dos fatores que constitui, diferencia, hierarquiza e localiza os sujeitos em nossa sociedade. (p.83)

De fato nem os cursos de psicologia e nem os de licenciatura, especialmente os de Pedagogia que formam profissionais para atuarem na educação infantil estão dando a devida importância às questões relativas a identidade racial. Para exemplificarmos a situação buscamos identificar em qual quadro referencial se construíram às imagens do bebê correspondente à representação utilizada pela professora. A partir de um exercício exploratório que consistiu em visitar o site brasileiro da empresa Johnson \& Johnson ${ }^{3}$ foi possível encontrar a preocupação em contemplar os diferentes grupos étnico-raciais quando se tratava de adultos. Porém, quando entramos no link intitulado Seu bebê, as cinco imagens de criança disponíveis eram exatamente como as descritas pelas duas professoras. Os bebês eram todos brancos de olhos azuis ou verdes. O uso de pessoas brancas, como norma, nas imagens publicitárias no Brasil, é um pequeno exemplo de que:

$3^{\urcorner}$Site $<\mathrm{http}: / /$ www.jnjbrasil.com.br> Acesso em 26 out. 2006.

Olh@res, Guarulhos, v. 2, n. 2, p. 203-226. Dezembro, 2014. 
De fato, tanto este traço de superioridade estética quanto o padrão de beleza de nossa cultura não é algo natural ou dado aos brancos. Mesmo assim, essa imagem de belo produz significados compartilhados, os quais os sujeitos se apropriam, singularizam, produzem sentidos e atuam sobre eles, de alguma forma reproduzindoos ou contrapondo-os. Na teia dialética em que a realidade social e o sujeito individual implicam-se mutuamente, a mediação semiótica exerce um papel fundamental. A linguagem e os significados compartilhados culturalmente funcionam como determinantes no processo de constituição de cada sujeito. Desta forma, os conteúdos racistas de nossa linguagem, bem como a ideia de superioridade racial branca construída no século XIX são ainda apropriados pelos sujeitos. E, nesse movimento da constituição da consciência individual, os significados alheios se tornam sentidos próprios. (SCHUCMAN, 2014, p.90)

A realidade brasileira constrói um ideal de branquitude como o desejável e isso acaba por incidir nas práticas pedagógicas com os bebês, como pudemos constatar na continuidade do exercício, desta vez, visitamos o site da empresa na sua versão em inglês. ${ }^{4}$ Ao entrar no site, as primeiras imagens que aparecem são, também, de crianças, brancas. Todas como as descritas pela professora. Porém, somos convidados a visitar vários links, inclusive um chamado: "visit.baby.com". Nele, as imagens apresentadas se alternam e de começo nos deparamos com uma mãe e seu bebê "gordinho e fofo". Sem ver a imagem ela nos parece idêntica àquela que as professoras descreveram como o tipo de bebê preferido por algumas profisssionais das instituições de educação infantil para dar colo e carinho. No entanto, nesse caso havia uma diferença substancial os "bebês Johnson" da página em inglês eram negros e asiáticos, todos "gordinhos e fofos". Essa página nos remete a um outro link correspondente ao do site brasileiro: Seu bebê. E qual não foi nossa surpresa, a primeira imagem de "bebê Johnson" que esse site apresenta é a de uma sorridente menina negra ${ }^{5}$, "gordinha e fofa".

Ou seja, o "bebê Johnson", na versão em inglês, podia ser negro, podia ser menina, contrariando consideravelmente a representação de "bebê Johnson" "gordinho e fofo" das professoras entrevistadas. Essa diversidade de imagens de bebês, apresentadas pela empresa Johnson \& Johnson só pôde ser encontrada na versão em inglês. Na versão brasileira, as únicas imagens de bebês 
as quais tivemos acesso na época do estudo, mostravam apenas um tipo físico, exatamente igual ao descrito pelas professoras como o tipo mais valorizado no ambiente da educação infantil. Refazendo uma parte do exercício, para a escrita desse artigo, sete anos depois, nos deparamos na página inicial da empresa ${ }^{6}$ no Brasil, com a seguinte situação: em destaque temos uma barriga sem rosto que se pode atribuir a uma mulher branca, uma mulher branca de olhos azuis divulgando produtos para combater o envelhecimento de pele, uma família composta de um homem, uma mulher, um filho e uma filha todos brancos e uma mulher e uma menina negra, a mãe de cabelo alisado e a filha com tranças africanas. Embora, ao entrar em outros links seja possível constatar ainda a predominância de pessoas brancas, a presença da imagem em que aparece a mãe e a filha negras indicam pequenas, mas positivas, mudanças no cenário publicitário que tange a representação de negros.

Os avanços identificados na publicidade também podem ser verificados em outros âmbitos da sociedade brasileira, inclusive no campo da formação de professores e professoras. Infelizmente não ocorre na proporção necessária e nem mesmo com o consenso esperado para o século XXI, ainda são ações pontuais, em geral, realizadas na formação continuada e não na inicial, mas estimulam questionamentos acerca de que

Considerando (ou quiçá inventando) seu grupo como padrão de referência de toda uma espécie, a elite fez uma apropriação simbólica crucial que vem fortalecendo a auto-estima e o autoconceito do grupo branco em detrimento dos demais, e essa apropriação acaba legitimando sua supremacia econômica, política e social. O outro lado dessa moeda é o investimento na construção de um imaginário extremamente negativo sobre o negro, que solapa sua identidade racial, danifica sua auto-estima, culpa-o pela discriminação que sofre e, por fim, justifica as desigualdades raciais. (BENTO, 2002, s/p).

Partindo da perspectiva de que é necessário, investimos em momentos formativos que ajudem os profissionais que atuam na educação infantil a desconstruir o imaginário negativo sobre a população negra e que temos uma parcela de responsabilidade para romper com tais hierarquizações, pois estamos formando profissionais nesse campo, organizamos ações formativas cujo objetivo foi construir junto a profissionais dessa etapa possibilidades de repensarem suas práticas pedagógicas desconstruindo o eurocentrismo nelas naturalizados, colaborando na formação de outras representações sobre as populações silenciadas 
pela branquidade normativa (GIROUX, 1999).

A trajetória de organização das experiências formativas passou por diferentes momentos, sempre orientados pela escuta dos/das participantes do GEPEDI inclusive os/as cursistas. A seguir apresentaremos algumas das questões vividas e aprendidas nessa partilha.

\section{As experiências de formação: uma caminhada, muitas estradas...}

O Grupo de Estudos e Pesquisas em Educação, Diversidade e Inclusão (GEPEDI), inicia suas atividades em novembro de 2009, com uma composição interdisciplinar da equipe, no qual uma das professoras trazia para o universo dos estudos e pesquisas a sua experiência com a educação especial, discutindo especificamente a escolarização das pessoas com necessidades especiais numa proposta de inclusão. A convergência dos objetos de trabalho ancorava-se nas discussões sobre as singularidades e diferenças dos sujeitos, salientamos que a educação especial é uma área de estudo que traz em seu bojo a discussão da diferença, haja vista que o imaginário social com relação à deficiência, apesar do discurso da inclusão, ainda se compõe com um olhar de ineficiência e incapacidade, tornando a escola muitas vezes um lócus de reprodução do preconceito, quando se espera da mesma a possibilidade de construção da alteridade. Esta articulação representa, também, um esforço das pesquisadoras em estabelecer conexões em diferentes projetos de pesquisa e de extensão, com seus campos de atuação. Buscou-se com esta experiência, romper com ações fragmentadas na formação de professores e professoras.

No caso específico deste grupo a articulação entre professoras com diferentes experiências torna-se mais fundamental, porque a diversidade é uma questão complexa, e de natureza interdisciplinar, pois se manifesta de formas diferentes nas regiões brasileiras, exigindo uma variedade de pesquisas que alcance as especificidades e particularidades que este conceito adquire nas distintas regiões do país, colaborando para o amplo debate social na construção de acordos entre os vários atores deste processo e para o aprimoramento dos conhecimentos desta área.

Balizados por essas concepções articuladoras realizamos o primeiro projeto de extensão, em 2010, intitulado “Educação Inclusiva e Diversidade na Olh@res, Guarulhos, v. 2, n. 2, p. 203-226. Dezembro, 2014. 
escola: desafios da escola para todos". Participaram deste Projeto cerca de 30 professores/ras da rede de ensino do município de Três Lagoas/MS, na sua maioria da Educação Infantil e também acadêmicos/cas dos cursos de História e Pedagogia do Câmpus da UFMS em Três Lagoas/MS.

O propósito foi trabalhar com os conceitos de educação inclusiva e diversidade com foco em relações étnico-raciais e necessidades educacionais especiais. Partindo das discussões possibilitar a professores e professoras que já atuam em escolas e centros de educação infantil e aos acadêmicos de Pedagogia e História a construção de aportes teóricos que lhes permitissem desenvolver práticas pedagógicas que rompam com processos discriminatórios e de exclusão, especialmente em relação a população negra e as pessoas com necessidades educacionais especiais consolidando o projeto emancipatório de educação de qualidade para todos.

O conceito de diversidade que norteou nossas ações no GEPEDI foi o mesmo presente no Relatório da Situação da Infância e Adolescência Brasileiras, publicado pelo UNICEF, resultado do I Seminário Criança Esperança, realizado em Brasília em junho de 2003. Isto é, partimos do pressuposto de que

A diversidade valorizada e celebrada não pode ser utilizada como uma maneira de eliminar as singularidades e as diferenças, mas, pelo contrário, como uma poderosa expressão de indignação e rejeição das iniqüidades que marcam as relações entre as pessoas e que tem por determinante exatamente a negação ou a subordinação e dominação em nome da diferença (UNICEF/BRASIL, 2003, pág. 12).

Com isso queríamos ao mesmo tempo reconhecer os limites de nossa discussão visto que não abarcávamos todas as manifestações das diversidades presentes no ambiente educacional e também assumirmos que estávamos dialogando a partir de pontos bem delineados, pois acreditamos que para a formação de profissionais identificados com uma política de educação inclusiva e promotora da igualdade é necessário especificarmos os campos e não tratá-los a todos como diversidade sem nomeá-los. Visto que cada área da diversidade requer instrumentos e ações distintas e só quando tratamos de suas especificidades é possível instrumentalizar os professores e professoras a produzirem um currículo que trabalhe em prol educação e conduza a mudanças concretas no cotidiano das escolas e centros de educação infantil no que tange as práticas que promovam a inclusão sem discriminação.

Também acreditávamos que alguns profissionais já desenvolviam Olh@res, Guarulhos, v. 2, n. 2, p. 203-226. Dezembro, 2014. 
práticas promotoras da diversidade tanto em relação as questões de identidade racial, quanto em relação a inclusão de pessoas com necessidades educacionais especiais e queríamos que elas pudessem ser identificadas para que fossem difundidas e reconhecidas entre os próprios pares e fossem apoiadas pela gestão escolar ampliando-as de modo a valorizá-las sendo tomadas como conteúdo essencial ao pleno desenvolvimento de crianças, adolescentes e jovens e se constituíssem como estratégia para erradicação do racismo e preconceito existentes na sociedade brasileira.

O curso durou de maio a agosto, com carga horária de 40 horas, com os seguintes módulos: I - Contexto Histórico das políticas de inclusão: deficiência e raça - 10h, II - Educação para todos: direitos e conflitos - 7h30m, III - Educação, preconceito e discriminação e as possibilidades de superação dos estigmas - 7h30m e Módulo IV - Produção de Projetos: didáticos e/ou de pesquisa $-17 \mathrm{~h}$, sendo que parte dessa carga horária foi realizada nas instituições.

As reflexões realizadas neste grupo mostraram a necessidade de pesquisas em Centros de Educação Infantil no município a fim de contribuir com a promoção de uma educação que contemplasse a todas as crianças, a partir de práticas inclusivas, tendo a diversidade como foco central. Assim, as discussões do GEPEDI se voltaram para a elaboração de um Projeto de Pesquisa que atendesse a essa demanda de estudo, projeto esse que foi aprovado na UFMS para ser desenvolvido nos anos de 2011 e 2012. Além disso os participantes solicitaram que fossem ofertados cursos de extensão com atividades práticas.

A pesquisa que ficou concentrada em dois Centros de Educação infantil e seus resultados apontara que as práticas tanto da inclusão de crianças com deficiências quanto ao tratamento das experiências com conteúdos relacionados a história e cultura afro-brasileira ainda possuem muitas fragilidades. Em relação à primeira questão concluímos que os professores/ras querem fazer um bom trabalho, mas precisam de mais orientação, pois existem tentativas de produção de práticas que atendam a diversidade, no entanto, elas ainda não estão suficientemente institucionalizadas e mesmo quando se tem os instrumentos para o desenvolvimento de boas práticas, apresenta-se o que podemos chamar de resistência dos/das professores/ras em utilizá-los, especialmente aqui estamos tratando de materiais didático-pedagógicos disponíveis que não são utilizados ou são subutilizados. Outra constatação da pesquisa foi que o preconceito racial está Olh@res, Guarulhos, v. 2, n. 2, p. 203-226. Dezembro, 2014. 
presente no espaço escolar da educação infantil, o que sugere que esta é uma questão que deve ser central nas discussões e debates entre os/as professores/ras e com as crianças e mesmo sem aparecer na pauta de reivindicações como um tema de formação, ele precisa ser trabalhado. Mas encontramos uma realidade positiva em relação a este fato de que houve silenciamento dos/das professores/ras diante das ofensas sofridas pelas crianças negras. Mesmo que o não silenciamento constitua um avanço em relação a realidades constatadas por pesquisas como a de Gonçalves (1985) ou Cavalleiro (2000), o fato dele estar relacionado a momentos específicos de conflitos reforça que as práticas promotoras da igualdade devem ir além de atuar nos conflitos especialmente com crianças tão pequenas. É necessário trazer para as práticas conhecimentos que colaborem para que as crianças construam uma ideia positiva de diversidade e rompam com os estereótipos, preconceitos e discriminações construídos socialmente.

Aqui surge nosso primeiro impasse em relação aos cursos de formação continuada há uma ânsia por parte dos/as cursistas de ações denominadas práticas. Muitos teóricos são contrários a qualquer tipo de indicação metodológica nesse sentido, pois as consideram "receitas educacionais", argumentam que se fornecemos constructos teóricos os professores e professoras serão capazes de alterar seus fazeres, pois terão o mais importante. De fato não há prática que sobreviva sem uma base teórica, mas sabemos que para os processos de formação terem impacto positivo é necessário a escuta dos sujeitos. Nesse sentido, após a finalização do curso a equipe se debruçou sobre as avaliações e constatamos que os pedidos para que novas ações fossem oferecidas, mas que essas tivessem atividades práticas expressavam o caráter conteudista que teve o curso, afora uma oficina de produção de bonecas que não sem explicação foi um dos momentos mais ricos da formação, os outros encontros foram pautados por apresentações expositivas seguidas de debates.

Tal concepção de formação pautada estritamente na transmissão de conhecimentos considerados legítimos e que a posse deles fará as transformações necessárias vem sendo criticada por vários teóricos e teóricas brasileiros. Catani (2010) nos convida a novos modos de organizando tais momentos.

Por fim, uma cultura de atenção encontra nesse momento terreno fértil para que tentemos transformar a educação de professores a partir de uma transformação de relações, consigo, com o outro e com o mundo. Tais são as dimensões vitais que temos sonegado em nossos processos educacionais. Seria talvez necessário que os aprendizados para a docência fossem

Olh@res, Guarulhos, v. 2, n. 2, p. 203-226. Dezembro, 2014. 
parte de um projeto de formação humanística mais enérgico quanto aos seus elos com as racionalidades cognitiva, ética e estética e menos ambicioso quanto aos seus anseios estritamente didático-pedagógicos. (p.91)

E foi revendo nossas estratégias formativas que organizamos o segundo curso de extensão, em 2012, com a firme conviç̧ão de que era necessário realizar mais atividades práticas. No entanto, nos orientou essa mudança a compreensão de que essas ações não podiam ser desprovidas de reflexões sobre a realidade, isto é, consideramos as atividades práticas como processos de ação reflexão - ação, isto é, como a possibilidade e analisar e refazer a prática educativa. Tomamos de empréstimo a explicação de Nakaschato (2012) sobre práxis para explicitarmos a nossa orientação nessa mudança de percurso.

[...] a práxis educativa é o cerne da atividade docente, uma vez que se busca a articulação dinâmica entre os interatores (mediadores e educadores), o conhecimento sistematizado e o contexto (espaços e tempos) do processo a fim de transformar a realidade objetiva. (p.75)

Nesse curso não pudemos contar com a colaboração da professora que trabalhava com as necessidades educacionais especiais - NEE, pois ela estava no doutoramento, então decidimos que a temática central seria a diversidade étnico-racial, mas pautaríamos as NEE.

O projeto foi intitulado "Na educação infantil também se promove a igualdade racial e a diversidade: formação de professores, investigação e desenvolvimento de práticas", contou com duas bolsistas e novamente foi possível estabelecermos a parceria com a Secretaria Municipal de Educação. Desta vez a carga horária foi de 50 horas, sendo que 20 deles deveria ser cumprida na realização de um projeto didático a ser desenvolvido pelas participantes em suas instituições. Foi oferecido exclusivamente para que atuava na educação infantil.

Organizamos os encontros a partir de temas: brincadeiras, música, leitura e arte. A cada encontro a sala era preparada como um "canto temático", expúnhamos os materiais relacionados a cultura afro-brasileira e incentivávamos as profissionais a manipulá-los. Elas reagiam com entusiasmo. A cada encontro a sala ia se apresentando com um tema novo e também com o visto anteriormente. Para cada um deles elas recebiam material teórico que seria discutido durante o encontro e nesse processo eram estimuladas a relatarem suas experiências com os temas, já tinha realizado alguma atividade que tratasse da diversidade étnico-racial Olh@res, Guarulhos, v. 2, n. 2, p. 203-226. Dezembro, 2014. 
e a música, a arte ou outro tema abordado. Algumas possuíam e compartilharam com as colegas, tornando o momento bastante rico.

As maiores dificuldades encontradas durante o processo de formação, neste caso, foi a adequação do horário, porque as professoras vinham para o curso em período alternativo a sua jornada de trabalho, ou seja, no noturno. Esse é outro limite quando se propõe a efetivar formação continuada, pois mesmo sendo parceira a Secretaria não liberava as profissionais para participarem dessa atividade em sua jornada de trabalho, se desonerando da responsabilidade de prover-lhes condições adequadas de formação. As participantes em sua grande maioria trabalhavam os dois turnos e participavam a noite da formação. Tal fato nos colocava sempre num impasse com a Secretaria de Educação, pois insistíamos na necessidade de que se disponibilizasse uma determinada carga horária dentro do regime de trabalho dessas profissionais, pois é de responsabilidade dos sistemas essa tarefa como está previsto nas Diretrizes Curriculares Nacionais para a Educação das Relações Étnico-Raciais e para o Ensino de História e Cultura Afro-Brasileira e Africana (2004). Segundo o documento que tem caráter mandatário, os sistemas devem garantir

Inclusão de discussão da questão racial como parte integrante da matriz curricular, tanto dos cursos de licenciatura para Educação Infantil, os anos iniciais e finais da Educação Fundamental, Educação Média, Educação de Jovens e Adultos, como de processos de formação continuada de professores, inclusive de docentes no Ensino Superior. (BRASIL, Diretrizes Curriculares Nacionais para a Educação das Relações ..., p. 23, grifos nossos)

Mas, infelizmente o que temos visto em relação a formação para este tema é mais uma ação voluntariada de professores e professoras do que uma política institucionalizada por parte dos sistemas educacionais, descumprindo frontalmente uma determinação legal. Nessas condições, o tempo era restrito para a leitura do material de apoio, discussões e interação com o material disponibilizado. Apesar disso consideramos que foi uma experiência exitosa, pois conseguimos despertar nas professoras da educação infantil a perspectiva de incluírem em suas práticas ações promotoras da igualdade étnico-racial. Vinte e seis pessoas finalizaram a formação e se organizaram em seis grupos de trabalho que elaboraram projeto didático, cujos temas foram: "Conhecendo outras culturas", "Origem dos negros no Brasil e outras culturas", "Diversidade desde a Educação Infantil", "Valorizando as diferenças Culturais", "A África no meu Olh@res, Guarulhos, v. 2, n. 2, p. 203-226. Dezembro, 2014. 
D.N.A: a cor da cultura, saberes, fazeres e modo de ver" e "Projeto dia da Consciência Negra. Destes apenas um grupo não desenvolveu o projeto na instituição onde atua, inclusive algumas apresentaram a produção realizada com as crianças no I Seminário da Educação Infantil promovida pela Secretaria de Educação e Cultura do município. O formato nos deixou bastante animadas e as avaliações também foram bem melhores que a primeira experiência de formação. Isso nos instigou a novas caminhadas no campo da formação para trabalhar na educação infantil o tema da diversidade étnico-racial.

Duas novidades foram incorporadas ao curso de formação de 2013 para o qual escolhemos um nome, muito parecido com o anterior "Diversidade Étnico-Racial: formação de professores, investigação e práticas”. Pela primeira vez nos sentimos capacitadas a incluir a temática indígena nas reflexões e também de forma ousadas nos propúnhamos a estender a ação para as instituições, ou seja, queríamos in loco, realizarmos algum tipo de intervenção. Também tivemos um salto qualitativo em relação ao espaço da formação nas políticas da Secretaria, nosso tema passou a fazer parte das ações previstas no cardápio de formação, com isso atingimos todos os polos pelos quais se organizam o órgão. Deste modo atingimos todas as unidades educacionais, por meio, dos representantes que participavam das formações (professoras, coordenadoras e diretores de centros de educação infantil).

Os principais objetivos do projeto, sempre se mantiveram o que íamos modificando eram as estratégias formativas. Nesta ação as linguagens da educação infantil e os eixos ludicidade e interação já presentes na anterior teve espaço maior e foram apresentados às professoras por meio de oficinas metodologias de confecção de Bonecas Abayomi ${ }^{7}$, confecção de brinquedos e brincadeiras de origem africana, afro-brasileira e indígenas e leituras tendo com eixo norteador o jogo simbólico, a ludicidade e interações que colaborem na valorização da cultura afro-brasileira e africana.

A ação se realizou em duas fases intercaladas. $\mathrm{Na}$ primeira trabalhamos com os/as professores/ras nos polos. Os membros do GEPEDI se deslocavam até a escola definida pela SMEC e realizávamos uma oficina teóricoprática para cerca de 40 professores/ras que representam sete instituições da

\footnotetext{
$7^{\urcorner}$Abayomi é uma boneca negra, de tecido, confeccionada sem costuras com referências da cultura africana, criada pela artesã Lena Martins em 1987. Para mais informações sobre esse tipo de boneca consultar o site 
região e que atendiam crianças da educação infantil de 0 a 5 anos e 11 meses. Para cada encontro foi trabalhada uma temática: jogo simbólico, brinquedos e brincadeiras, leitura, música e artes, sobre as quais desde a primeira experiência tínhamos acumulado um repertório de práticas e materiais que se relacionam diretamente com o currículo e as linguagens próprios da educação infantil.

Buscamos fazê-los/as, vivenciarem alguns momentos que permitiam a reflexão sobre a importância de incluir temáticas relacionadas a cultura afro-brasileira e africana no currículo da educação infantil, mas sobretudo buscamos mobilizá-los/as a partir das vivências alterarem suas práticas. Cada instituição participante recebeu um conjunto de textos e também um modelo de Projeto Didático com o tema tratado que poderá ser desenvolvido junto às crianças de 3 a 5 anos.

$\mathrm{Na}$ primeira oficina, para exemplificar o desenvolvimento da formação, foi enfatizada a importância do jogo simbólico e para isso utilizamos como argumento a exposição de bonecas/cos de diferentes tipos étnicos-raciais, com forte presença de bonecas negras de distintos materiais (pano, industrializadas, artesanais) e depois a confecção das Abayomi com as quais trabalhamos as questões da diversidade étnico-racial, do reconhecimento da cultura afro-brasileira articulados ao faz de conta. Também foram utilizados outros jogos como o avatar da identidade ${ }^{8}$, no qual a própria pessoa constrói seu corpo, escolhendo a cor da pele, o tipo de cabelo, podendo mudar quando julgar adequado.

Ao final, apresentávamos ao grupo um modelo de Projeto Didático elaborado por nós do GEPEDI, para que pudessem com as devidas adaptações desenvolvê-los em suas instituições e uma delas receberia o apoio do grupo na sua realização, o que se configurou como a segunda fase da nossa ação formativa.

$\mathrm{Na}$ segunda etapa o projeto foi desenvolvido em duas instituições de educação infantil, entre julho e setembro de 2013 membros do GEPEDI. Foi realizado em uma sala de Pré-escolar I (crianças de 04 a 05 anos) numa ação de parceria entre a UFMS e a escola.

Íamos até a instituição conversávamos com a coordenação, apresentando o projeto e a lista de materiais necessários. Enfatizávamos que

\footnotetext{
$8^{\urcorner}$Este material didático foi criando por Bárbara Fagundes Lima, acadêmica do curso de Pedagogia de Três Lagoas/MS, no âmbito da disciplina Tópicos Especiais em Educação para a igualdade étnico-racial cursada por ela em 2011 e tem sido utilizado pelo GEPEDI nas atividades de formação, com ótimos resultados.

Olh@res, Guarulhos, v. 2, n. 2, p. 203-226. Dezembro, 2014.
} 
estaríamos ali para colaborar na efetivação do projeto, mas gostaríamos que a professora da turma onde iria se realizar assumisse o trabalho como uma ação dela, pois queríamos que a professora solicitante assumisse a execução do projeto como uma ação sua e não externa.

Não será possível relatar aqui as muitas questões que pudemos vivenciar e que seriam de grande importância nos debruçarmos sobre elas no sentido de aprimorar as questões que a experiência nos trouxe, especialmente, em relação às atitudes, falas, reações das crianças. Porém a título de exemplo, vale relatar alguns pontos da primeira atividade realizada em uma das instituições.

Por coincidência, segundo relato da professora que nos recebeu uma criança na semana anterior a nossa chegada havia levado uma boneca negra que tinha sido rejeitada por vários colegas. Ela também nos contou que questionou as crianças sobre essas opiniões negativas. Para dar início ao projeto as crianças foram recebidas em sala com bonecas de diferentes pertencimentos étnico-raciais (inclusive bonecas com difidências, cadeirante, cegas e com síndrome de down) estavam nas cadeiras, em cima das mesas e no chão. Quando as crianças chegaram olhavam para as bonecas, mas não as tocavam. Somente depois que uma das crianças nos perguntou se poderia pegá-las e dissemos que sim elas interagiram com os brinquedos.

Não percebemos uma rejeição coletiva em relação as bonecas negras, mas constatamos os impedimentos em relação a questão de gênero. Um menino só se aproximou quando uma das acadêmicas apresentou-lhe um boneco e ele disse: "com esse [o boneco] eu posso brincar", outra situação muito instigante foi de uma menina negra que negou-se, nos primeiros momentos a tocar nas bonecas negras, escolhendo somente as brancas e só muito tempo depois com a intervenção de uma das bolsistas ela aceita a boneca negra que de acordo com ela "se parecia com ela". As experiências com as crianças são ricas e os modos como reagem a proposta nos fazem acreditar que o caminho é fértil e promissor, pois as respostas positivas em relação a diversidade e apropriação das discussões sobre a valorização das diferenças é muita rápida, além disso os relatos das professoras sobre a atitude das crianças após o desenvolvimento são muito animadores visto que elas tendem a expressar mais solidariedade e menos preconceitos na relação uns com os outros, mas essa questão é matéria para outro artigo.

Infelizmente nossa proposta era ir a uma escola de cada polo, no 
entanto, por questões internas a Secretaria suspendeu as formações por dois meses, o que inviabilizou a continuidade da proposta desta segunda etapa. Foram ainda tratados os Brinquedos e Brincadeiras de origem africana e indígena quando destacamos as inúmeras contribuições desses grupos para a cultura lúdica brasileira, incentivando-os a confecção de brinquedos com materiais reciclados. $\mathrm{Na}$ oficina 3, discutimos, ouvimos e dançamos a musicalidade e música brasileira enfatizando a contribuição dos povos africanos e indígenas na sua constituição. Nesta Oficina apresentamos instrumentos de origem africana e indígena que fazem parte da nossa cultura destacando que música é uma forma de expressão da cultura do Brasil e traz nas suas origens e nos instrumentos musicais uma grande influência africana e indígenas e os/as professores/as foram convidados a confeccionarem pelo menos um instrumento com sucata que remeteu a instrumentos musicais africanos, afro-brasileiros ou indígenas.

A estética e o corpo também foram objetos da quarta oficina, por serem importantes construtores de autoestima enfatizamos penteados africanos e seus significados relacionando-os aos "jeitos de ser" do brasileiro. Nesta Oficina foi dado destaque aos penteados masculinos e femininos, especialmente aqueles que podem ser feitos em cabelos crespos, pois sabemos que o preconceito racial é manifestado de várias formas, sendo as mais comuns dirigidas a cor da pele e ao cabelo crespo, sendo este relacionado mais com a figura feminina. Preocupadas com esta questão e buscando valorizar a beleza dos cabelos crespos também dos meninos, nessa oficina apresentamos penteados africanos que podem ser feitos em todos os tipos de cabelos, os adereços de cabelos e questões históricas relacionadas com os penteados africanos e aqui também elas foram convidadas a realizarem penteados em si e nas outras colegas.

A leitura e a diversidade foram presentes na oficina 5 , pois a literatura é um grande recurso de divulgação e ampliação de valores. Nesta oficina os/as professores/ras foram apresentados a um acervo de livros que tratam da diversidade cultural e física, destacando de modo positivo, personagens negros e deficientes, dentre outros que sofrem discriminação. Elas foram chamadas a confeccionar um livro por meio de releituras do acervo disponibilizado ou mesmo de criando história inédita que de algum modo, possibilite o contado com a diversidade por meio desse suporte.

E por fim, a arte como manifestação das expressões, dos Olh@res, Guarulhos, v. 2, n. 2, p. 203-226. Dezembro, 2014. 
sentimentos de um povo, de uma cultura foi tratado na oficina 6 . Nesta, trabalhamos com máscaras e cerâmicas. Enfatizando que a arte é expressão de vida e por isso revela muito das crenças e valores de um povo. A arte está sempre associada aos eventos sociais e atividades cotidianas, mostramos $\mathrm{s}$ a arte de povos africanos e afro-brasileiros e indígenas reveladas nas pinturas corporais, artesanais e principalmente nas máscaras. Propusemos a confecção de cerâmicas e máscaras que podem ser trabalhadas depois com as crianças, explorando as texturas, as cores, os tamanhos, etc.

\section{Considerações finais}

As atividades formativas foram exitosas e em cada uma delas os momentos de avaliação foram muito ricos para revermos o percurso e estabelecermos novas metas, pois não há um único caminho nesse processo. $\mathrm{O}$ que pudemos apreender é que mesmo sem as condições ideias para realizá-las, especialmente, no que diz respeito ao horário de trabalho, há sempre profissionais interessados em discutir e repensar o lugar da diversidade étnico-racial no currículo da educação infantil. Nas três ofertas tivemos todas as vagas preenchidas e a desistência ficou dentro do esperado, cerca de $15 \%$. Os cursistas respondem com mais entusiasmo quando as propostas envolvem reflexão aliada a vivências e menos, se nos centramos em estudos de textos e discussões.

A última versão na qual nos dirigimos a instituição não teve o êxito esperado porque percebemos que a nossa intenção inicial de apoiar a profissional no seu local de trabalho para o desenvolvimento do projeto para que houvesse uma apropriação do que foi trabalhado na formação e ela pudesse conduzir as mudanças em suas práticas não se realizou. Elas foram muito solícitas, participando de todas as atividades, quase como uma das crianças. A confecção da boneca, por exemplo, uma delas fez com esmero, porém não assumiu o projeto como esperávamos.

Nas salas a equipe do GEPEDI coordenou as ações e as professoras, no máximo colaboraram. O que nos coloca novas questões acerca da formação em serviço e a contribuição da universidade. Para fins de pesquisa nos parece adequado que estejamos no ambiente educacional, no entanto, para a parceria no sentido do projeto ser assumido pelas profissionais julgamos que o 
Educação infantil e a diversidade étnico-racial: experiência de formação e seus desafios

adequado é estabelecermos outras formas de interação, talvez após a primeira fase solicitar que desenvolvam o projeto e ir acompanhando esse processo com discussões paralelas, mas não pareceu conveniente que estivéssemos juntos em sala.

Além dessas reflexões que orientarão novas atividades formativas, após esses três anos foi possível consolidar alguns princípios orientadores para a formação de professores/ras com foco na diversidade étnico-racial, quais sejam:

- Trabalhar a diversidade como um valor humano;

- Garantir o eixo da ludicidade na abordagem da diversidade étnico-racial na educação infantil;

- Desenvolver metodologias que subsidiem experiências com foco na diversidade étnico-racial na educação infantil;

- Incentivar a reorganização do currículo por meio de projetos didáticos;

- Organizar momentos em que os professores e professoras possam experienciar algumas práticas pedagógicas a serem desenvolvidas com as crianças

Ainda nos preocupa que o fato de que embora as professoras fiquem entusiasmadas e participem ativamente das oficinas, reconhecendo a importância do tema e a pertinência de a incluírem em suas práticas elas não se sentem seguras ou suficientemente motivadas a realizarem as ações aprendidas nas salas onde atuam. Nesse sentido, acreditamos que seja necessário desenvolver pesquisas sobre os motivos que levam os/as professores/ras a participarem das ações formativas, reconhecerem a importância do tema, receberem ferramentas, como o modelo de um projeto pedagógico, atividades práticas e mesmo assim ainda não incluírem em suas práticas pedagógicas ações na perspectiva da diversidade étnico-racial. 


\section{Referências}

BENTO, M. A. S, SILVA JR. H., DIAS, L. R. Educação infantil, diversidade e igualdade etnicorracial. Trabalho encomendado, 33 ${ }^{\mathrm{a}}$ reunião Anped, 2010.

BENTO, Maria Aparecida Silva. Branqueamento e branquitude no Brasil. CARONE, Iray, BENTO, Maria Aparecida Silva (orgs). In: Psicologia social do racismo: estudos sobre branquitude e branqueamento no Brasil. Petrópolis, RJ: Vozes, 2002, p. (25-58) Disponível em: $<\mathrm{http}: / /$ midiaetnia.com.br/wp-

content/uploads/2010/09/branqueamento_e_branquitude_no_brasil.pdf $>$ Acesso em Nov. 2014.

BRASIL. Constituição (1988). Constituição da República Federativa do Brasil. Brasília, DF, Senado,1998.

BRASIL. Lei no 9394 de 20 de dezembro de 1996. Estabelece as Diretrizes e Bases da Educação Nacional. Diário Oficial da União, Brasília, DF, 23 de dezembro de 1996.

BRASIL. Conselho Nacional de Educação/Conselho Pleno. Parecer no 3, de 10 de março de 2004. Institui Diretrizes Curriculares Nacionais para a Educação das Relações Étnico-Raciais e para o Ensino de História e Cultura Afro-Brasileira e Africana. Diário Oficial da União, Brasília, DF, Seção I, 22 de junho de 2004.

BRASIL. Conselho Nacional de Educação/ Conselho Pleno. Parecer CNE/CP no 20, de 11 de novembro de 2009. Institui as Diretrizes Curriculares Nacionais para a Educação Infantil. Diário Oficial da União, Brasília, DF, 09 de dezembro de 2009.

Brasil. Ministério da Educação. Secretaria de Educação Básica. Diretrizes curriculares nacionais para a educação infantil / Secretaria de Educação Básica. - Brasília: MEC, SEB, 2010.

CAVALLEIRO, Eliane. Do silêncio do lar ao silêncio escolar: racismo, preconceito e discriminação na educação infantil. São Paulo: Contexto, 2000.

CATANI, D. Por uma pedagogia da pesquisa educacional e da formação de professores na universidade. Revista Educar, Curitiba, n. 37, p. 77-92, maio/ago. 2010. Editora, UFPR. 
DIAS, Lucimar Rosa. No fio do horizonte: educadoras da primeira infância e o combate ao racismo. Tese (Doutorado em Educação) - São Paulo: Universidade de São Paulo, 2007.

NAKASCHATO, Guilherme. A educação não formal como campo de estágio: contribuições na formação inicial do arte/educador. São Paulo, Editora: SESI -SP (Prata da casa, Programa Publique-se), 2012.

GIROUX, Henry A. Por uma pedagogia e política da branquidade. Cadernos de Pesquisa, $\mathrm{n}$. 107, p. 97-132, jul. 1999.

GONÇALVES, Luiz Alberto. O silêncio: um ritual pedagógico a favor da discriminação. Belo Horizonte, 1985. Dissertação - Faculdade de Educação, Universidade Federal de Minas Gerais.

SILVA JUNIOR, H. Direito de Igualdade Racial: aspectos constitucionais, civis e penais, doutrina e jurisprudência. São Paulo: Editora: Juarez de Oliveira, 2002.

. Discriminação racial nas escolas: entre a lei e as práticas sociais Brasília: UNESCO, 2002.

SILVA, P. V. B. O Silêncio como estratégia ideológica no discurso Racista Brasileiro. Currículo sem Fronteiras, v.12, n.1, pp.110-129, Jan/Abr 2012.

SCHUCMAN, L. V. (2014). Sim, nós somos racistas: estudo psicossocial da branquitude paulistana. Psicologia \& Sociedade, 26(1), 83-94

UNICEF. Situação da Infância e Adolescência Brasileira (Relatório), 2003. Disponível em: $<$ http://www.unicef.org/brazil/pt/siab03_1.pdf> Acesso em Nov. 2014.

UNESCO. Declaração de Salamanca. Sobre Princípios, Políticas e Práticas na Área das $\begin{array}{llll}\text { Necessidades Educativas } & \text { Especiais. }\end{array}$ $<$ http://portal.mec.gov.br/seesp/arquivos/pdf/salamanca.pdf $>$ Acesso em: 28 maio 2009. 